\title{
Treatment paradigms for oligometastatic pediatric cancers: a narrative review with a focus on radiotherapy approaches
}

\author{
Timothy D. Smile ${ }^{1}$, Shireen Parsai ${ }^{1}$, Travis M. Pflederer ${ }^{2}$, Erin S. Murphy ${ }^{1}$ \\ ${ }^{1}$ Department of Radiation Oncology, Taussig Cancer Institute, Cleveland Clinic, Cleveland, OH, USA; ${ }^{2}$ College of Medicine, University of Illinois at \\ Chicago, Chicago, IL, USA \\ Contributions: (I) Conception and design: All authors; (II) Administrative support: All authors; (III) Provision of study materials or patients: None; \\ (IV) Collection and assembly of data: All authors; (V) Data analysis and interpretation: All authors; (VI) Manuscript writing: All authors; (VII) Final \\ approval of manuscript: All authors. \\ Correspondence to: Timothy D. Smile, MD. 9500 Euclid Ave/CA-50, Cleveland, OH 44195, USA. Email: smilet@ccf.org.
}

\begin{abstract}
There is a growing body of prospective evidence describing an oligometastatic phenotype in adults for whom local metastasis-directed therapy can improve outcomes in select patients. However, a relative paucity of data for pediatric patients with oligometastatic disease creates challenges in choosing optimal treatment. The purpose of this review is to evaluate the literature surrounding pediatric oligometastatic disease and treatment, specifically focusing on the role of radiotherapy. A review of studies ranging from 2008 to 2020 was performed. The radiotherapy techniques evaluated included conventionally fractionated radiotherapy, stereotactic body radiotherapy (SBRT), and stereotactic radiosurgery (SRS). Our search yielded 6 studies evaluating conventionally fractionated radiotherapy, 9 studies of SBRT, and 3 studies of spine SRS. Metastasis-directed therapy for treatment of pediatric oligometastasis is generally well-tolerated, is associated with favorable local control, and is shown to improve event-free survival and progression-free survival (PFS) outcomes in select pediatric patients. Pediatric patients with oligometastatic disease may benefit from aggressive local therapy to metastatic sites in conjunction with a comprehensive treatment paradigm. Retrospective data have led to promising prospective trials that will further clarify patient selection and management. Additional data are needed to elucidate long term oncologic and toxicity outcomes.
\end{abstract}

Keywords: Oligometastasis; pediatric cancer; radiotherapy; stereotactic body radiotherapy (SBRT)

Submitted Apr 25, 2020. Accepted for publication Sep 23, 2020.

doi: 10.21037/apm-20-1023

View this article at: http://dx.doi.org/10.21037/apm-20-1023

\section{Evidence for treatment of oligometastatic disease in pediatric malignancies}

There were an estimated 11,050 new diagnoses of cancer in children ages $0-14$ years in 2019 with an estimated 1,190 cancer deaths in children ages 1-14 years (1). Of these newly-diagnosed children, those presenting with metastatic disease at initial diagnosis have lower 5 -year survival rates, particularly those with sarcomas. Metastases in children with cancer have been treated with a definitive intent across many diseases including neuroblastoma (2), Wilms tumor (3-5), rhabdomyosarcoma (6,7), medulloblastoma (8), and Ewing's sarcoma $(6,9)$. However, there is limited data evaluating oligometastatic disease specifically in childhood cancer.

There is a growing body of evidence in the adult patient population describing a spectrum of metastatic cancer ranging from a single site of oligometastasis to a widelymetastatic incurable state (10). Historically, metastatic disease in adults with cancer diagnoses was treated with palliative intent. With careful patient selection and recent advances in systemic therapy, durable disease control has become achievable with the addition of aggressive local therapy for some adult patients with limited systemic disease 
(11-15). A growing body of phase II evidence demonstrates improvements in progression-free survival (PFS) and overall survival (OS) with definitive and ablative radiotherapy to primary and oligometastatic sites of disease.

In the pediatric, adolescent, and young adult population, Ewing sarcoma serves as an example of a diagnosis in which metastatic disease has been evaluated, categorized, and treatment approaches are in development. Twentyfive percent of patients with Ewing sarcoma present with metastatic disease at the time of diagnosis (16). Patients with metastatic Ewing sarcoma limited to lung and bone are considered curable with aggressive local therapy. Surgical metastasectomy of pulmonary oligometastasis leading to long-term event free survival has been described in case studies dating back to the late $19^{\text {th }}$ century (17) with more recent data demonstrating durable disease-free survival in select patients $(18,19)$. The Euro-EWING 99 trial was a prospective multi-institutional trial of chemotherapy followed by local therapy to the primary tumor and/or sites of metastases, followed by consolidation chemotherapy and autologous stem-cell transplantation for pediatric Ewing sarcoma patients with multiple extrapulmonary metastases (9). The trial provided prognostic risk factors for event-free survival and OS including age, tumor volume and extent of metastatic spread. A secondary analysis demonstrated the importance of adding aggressive local therapy to sites of metastatic disease to systemic therapy for patients with primary disseminated metastatic Ewing sarcoma (PDMES) (16). In this collaborative analysis, 120 patients with PDMES to locations other than lung received either no local treatment, local treatment to their primary or metastatic disease, or local therapy to both primary and metastatic disease. Conventionally fractionated radiotherapy - either alone or in combination with surgery - was utilized as local therapy to the primary tumor in $51 \%$ of patients and to metastatic disease in $40 \%$ of patients. Significant 3-year event free survival benefit $(\mathrm{P}<0.001)$ was seen in patients receiving local therapy to primary and metastatic disease (39\%) compared to those with less than comprehensive local therapy $(17 \%)$ or no local therapy (14\%).

Local therapy included surgery and/or radiotherapy either concurrently with chemotherapy or adjuvantly. Interestingly, although patients with true oligometastatic disease had the largest benefit, those with 2 to 5 and $>5$ had significant improvement in EFS as well (on univariate analysis), demonstrating that aggressive local therapy may benefit patients with metastatic disease regardless of number of metastases.

While data is limited characterizing the oligometastatic paradigm in other disease sites, there is evidence suggesting improved outcomes in Rhabdomyosarcoma patients with oligometastasis as observed in the Intergroup Rhabdomyosarcoma Study IV (20). In this trial of children treated with two variable chemotherapy regimens with otherwise standard of care therapy, multivariate analysis demonstrated improved 3-year OS and failure-free survival (FFS) rates for patients with two or fewer metastatic sites, regardless of histology, although embroyal patients with $\leq 2$ metastatic sites showed 3-year FFS of $40 \%$ and OS of $47 \%$. We present the following article in accordance with the NARRATIVE REVIEW reporting checklist (available at http://dx.doi.org/10.21037/apm-20-1023).

\section{Role for radiotherapy in metastasis-directed therapy}

\section{Conventional radiotherapy}

Radiotherapy is a well-established treatment modality for improving local and regional control outcomes in the definitive, adjuvant and neoadjuvant settings across a spectrum of pediatric diseases.

Conventionally fractionated adjuvant and/or definitive radiotherapy is standard of care for definitive management of multiple types and stages of pediatric solid tumors (2-9). Conventional radiotherapy has been utilized as metastasisdirected therapy in multiple studies (16,21-25). As noted above, conventionally fractionated RT was a component of aggressive local therapy reviewed by Haeusler et al. in the secondary analysis of the Euro-E.W.I.N.G trial (16). Out of the 120 patients in the study, 21 patients received surgery and RT to the primary tumor, 40 received definitive RT to the primary, 9 received surgery and RT to metastases, and 33 received definitive RT to metastases. The authors reported a significant event-free survival benefit at 3 years for patients who underwent local therapy to involved primary and metastatic sites. Another recent retrospective study by Grewal et al. demonstrated significantly improved PFS among metastatic Ewing sarcoma patients who received metastasis-directed RT compared to those who had treatment to primary tumor alone (21). When considering extent to which local control should be delivered in local RT for metastatic rhabdomyosarcoma patients, there is retrospective data suggesting improved outcomes with comprehensive local treatment to all metastatic sites (22). 
The study included 35 pediatric patients, median age was 6.5 years (range, 1-16), with newly diagnosed stage IV rhabdomyosarcoma treated with palliative RT at Texas Children's Hospital. Distant metastatic sites included lung (57\%), distant lymph nodes (31\%), bone (29\%), soft tissue (26\%) and bone marrow (11\%). The authors reported 5 -year PFS and OS estimates of $20 \%$ and $25 \%$, respectively, for the entire cohort. However, the 5-year PFS and OS were $31.3 \%$ and $37.3 \%$, respectively, in patients receiving local therapy to all sites of distant metastasis $v$ s. $0 \%$ and $0 \%$ in those receiving local therapy to less than all sites $(\mathrm{P}=0.002)$. Metastasis-directed therapy outcomes have also been reported among pediatric neuroblastoma patients in a small retrospective series (23). Of 37 patients with stage 4 neuroblastoma, 13 patients $(35 \%)$ received metastasisdirected RT. The authors reported no significant 5-year OS or relapse-free survival difference with or without metastasis-directed RT. For further details on these data, Table 1 is a summary of recently published studies investigating conventional radiotherapy for metastasisdirected therapy for pediatric patients.

\section{Advances in radiotherapy}

\section{Stereotactic body radiotherapy (SBRT)}

Historically, radiotherapy was almost exclusively delivered with fractionated courses using $2 \mathrm{D}$ treatment planning methods. Improvements in imaging and treatment modalities have led from $3 \mathrm{D}$ conformal treatments to intensity-modulated radiotherapy (IMRT) with image guidance, now resulting in ability to deliver more precise and conformal treatment plans with lower radiation doses to normal structures than in the past. With this increase in conformality and precision came the concept of hypofractionation in which biologically equivalent doses of radiation were given in fewer treatments with higher dose per fraction. When hypofractionation was shown to be safe and efficacious for many diseases, the concept was taken further with the emergence of extreme hypofractionation by means of SBRT regimens. SBRT is generally categorized as 5 or fewer fractions of $\geq 6$ Gy per fraction $(24,26)$. With emerging data in the past two decades demonstrating the safety and efficacy of SBRT and SRS in adult patients, these techniques are now being studied in pediatric patients.

Caring for pediatric cancer patients presents challenges that are unique compared to adult patients. These younger patients may still be growing and developing, and therefore radiotherapy doses to their normal tissues risk causing more significant late toxicities. Also, some of these patients require daily anesthesia for their treatments. Some of these challenges cause radiation oncologists to favor shorter courses of highly-focused, hypofractionated radiotherapy. Hypofractionated RT allows for accelerated return to systemic therapy, which is the backbone of many pediatric cancer treatment paradigms. It also allows for patients who are students to more quickly return to school and/or to their normal routines, and results in less burden to families with fewer visits to the radiation oncology department. With regard to toxicity, stereotactic radiotherapy allows for utilization of motion management systems that allow for smaller PTV expansions and utilizes multiple highly conformal beams which results in less exposure of normal tissue.

While mostly limited to single-institution retrospective series, there are some compelling data reporting outcomes with the use of SBRT in pediatric patients which can apply to oligometastatic patients (27-38).

\section{SBRT-bone metastases}

Two series reported in abstract form only, included patients with multiple histologies including neuroblastoma, Ewing sarcoma, rhabdomyosarcoma, and others $(27,28)$. SBRT for recurrent and metastatic osseous disease in pediatric patients was again associated with excellent local control and low rates of serious toxicity in a retrospective series from Memorial Sloan Kettering Cancer Center (27). Fifteen patients with 20 lesions were treated with SBRT with median dose of 27 Gy in 3 fractions (range, 20-40 Gy, 3-5 fx). Local control at median follow-up of 22 months was $75 \%$, and crude rate of grade 3 toxicity was $15 \%$. Of note, 12 of the 20 lesions had previously been treated with radiotherapy. Another retrospective series from St. Jude Children's Research Hospital reported outcomes for 33 pediatric patients with 69 metastatic or recurrent lesions treated with SBRT of which 41 were treated with curative intent and 28 with palliative intent (28). Median dose was 40 Gy (20-41 Gy) with median dose per fraction of 6 Gy (range, 5-8 Gy). Radiographic response rate-which included complete response or stable disease-was $91 \%$ for bone lesions and $71.4 \%$ for soft tissue lesions. Median duration of best response was 19.1 and 7.5 months per site, respectively. Local control at 1 year was $77.4 \%$ with no observed acute or late toxicity of grade 3 or higher. The 16 local recurrences were described by site with 5 in-field, 9 


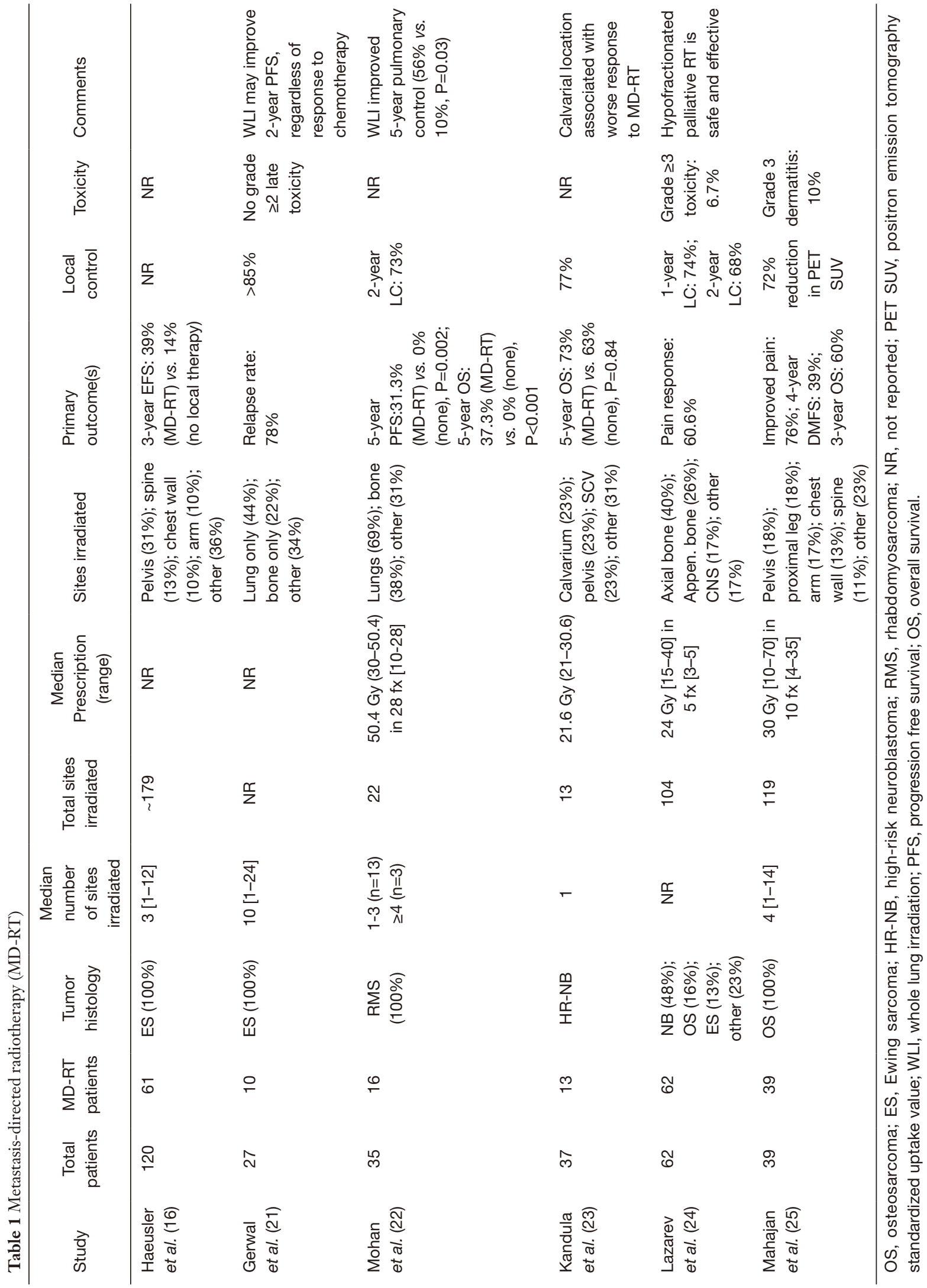


marginal, and 1 outside local failures.

\section{SBRT-sarcoma metastases}

There have been multiple studies examining SBRT specifically for treatment of metastatic sarcoma in patients that can be applied to pediatric patients with oligometastatic disease. Brown et al. reported favorable control outcomes with SBRT in patients with metastatic Ewing sarcoma and osteosarcoma (29). This retrospective series from Mayo Clinic included 14 pediatric patients with 27 lesions of recurrent or metastatic Ewing sarcoma or osteosarcoma treated with SBRT. With a median dose of 40 Gy in 5 fractions, 2-year local control was excellent at $85 \%$ with no grade 3 or greater acute toxicity reported. Late toxicity was seen in three patients with one grade 3 (sacral plexopathy) and two grade 2 (myositis, pathologic fracture/avascular necrosis) toxicities. These adverse events are discussed further in the "Toxicity for Aggressive Local Therapy" section below. A Swedish retrospective series by Stragliotto et al. examined dosimetric relationship to local control and toxicity in 46 patients with 136 foci of metastatic sarcoma treated with SBRT (30). While $67 \%$ of patients in this cohort underwent SBRT to multiple metastatic lesions, the authors did not further define metastatic or oligometastatic disease. The age range of the cohort was $8-87$ years old. Overall response rate-defined as complete response, partial response, or stable disease-for all evaluable tumors was $88 \%$ at median follow-up of 21 months. Ten patients with Ewing/PNET or osteosarcoma histologies received treatment to 30 lesions. Local control with SBRT was $86 \%$ for Ewing/PNET lesions ( $\mathrm{n}=14)$ and $75 \%$ for osteosarcoma lesions $(n=16)$. Severe toxicity was seen in two patients, one of whom developed a colon perforation and another who had contracture of the hip region. Otherwise, the authors report at least one side effect was reported in 68\% of patients, most commonly cough and dyspnea. Another single-institutional retrospective series reported outcomes for SBRT to recurrent or metastatic sarcoma (31). The investigators included 24 patients ages $8-86$ years old with median age of 30 years. While the study included both children and adults, $46 \%$ of patients had histology of either Ewing sarcoma (25\%) or osteosarcoma (21\%) suggesting applicability to pediatric patients. Median dose was $30 \mathrm{~Gy}$ (8-40 Gy) delivered in 5 fractions [1-10]. The authors did not report the number of lesions treated. Again, SBRT was associated with excellent local control of $96 \%$ at median follow-up of 5.9 months. There were no grade 3 toxicities reported, and grade 1-2 acute toxicity was seen in $25 \%$ of patients. A retrospective series from the Cleveland Clinic demonstrated favorable outcomes with SBRT for pediatric, adolescent and young adult patients with metastatic sarcoma (32). In this series, 22 patients underwent SBRT to 61 metastatic lesions with a median dose of 35 Gy (range, 16-60) in 5 fractions (range, 1-5) with a median PTV size of $40 \mathrm{cc}$ (range, 4-806). Local control was $87 \%$ at 6 months and $77 \%$ at 12 months. There was no grade $\geq 3$ acute toxicities reported, and grade 1-2 acute toxicity was seen in $23 \%$ of patients. With regard to late toxicity, one patient experienced grade 3 radiation enteritis of the jejunum after undergoing re-irradiation to L3. Of note, this patient experienced the enteritis after exposure to gemcitabine and docetaxel 3 months after re-irradiation with SRS.

\section{SBRT-lung metastases}

With regard to efficacy and safety of SBRT for lung metastases in pediatric malignancies, a case series from SUNY Upstate Medical University reported favorable outcomes. Three patients were treated with SBRT for 12 pulmonary lesions consisting of rhabdoid tumor, Ewing sarcoma and Wilms tumor histologies (33). Two of the three patients underwent SBRT for a single lung lesion, while one patient with metastatic rhabdoid tumor underwent SBRT to 10 lung lesions over a 2-year period. SBRT doses ranged from $37.5-50$ Gy in 3 to 5 fractions, and local control was $100 \%$ at minimum follow-up of 1.9 years. There were no observed acute toxicities. One patient developed a late grade 2 rib fracture that may have been related to SBRT. The patient with Wilms tumor experienced durable disease-free survival without whole lung RT or further systemic therapy.

\section{Spine stereotactic radiosurgery (SRS)}

Anatomical location and histology can also guide the use of SBRT in oligometastatic pediatric patients for whom the line between definitive and palliative therapy is not clear. For example, radioresistant histologies like sarcomas that present with metastases in the spine present a significant risk of morbidity with local progression. There are compelling data suggesting safety and efficacy of aggressive local control with ablative doses of RT for metastatic spinal sarcomas $(31,34,35,39-43)$. While safety and efficacy outcomes can often be extrapolated to young patients, there are fewer studies that reviewed outcomes in the pediatric population. A series from South Korea studied outcomes for 27 patients 
ages 11-65 years old with sarcomas of the spine treated with SRS, 17 of whom received treatment to metastatic lesions (34). In this trial, $52 \%$ of patients had osteosarcoma, and median single-session equivalent dose was $21.8 \mathrm{~Gy}$. Local control at 6 months and 24 months was $96.7 \%$ and $76.9 \%$, respectively. Median local PFS for primary and metastatic sarcoma was 41 vs. 23 months, respectively, although this was not statistically significant. On multivariate analysis, age $\geq 46$ years was a risk factor for worse local PFS compared to younger age (16 vs. 59 months, $\mathrm{P}=0.009)$. A series from Cleveland Clinic reported outcomes for 7 adolescent and young adult patients ages 15-29 years old undergoing spine SRS for 11 lesions of metastatic osteosarcoma and Ewing sarcoma (36). Median SRS dose was 35 Gy [16-40] in 5 fractions [1-5], which led to $64 \%$ local control rate at median follow-up of 11.1 months (6.8-26.0 months) due to local failures in three lesions. Of the three local failures, the two osteosarcoma failures were marginal, and the one Ewing sarcoma failure was in-field. While there were no acute grade 3 or higher toxicities, one patient developed late grade 3 radiation enteritis, although this patient had received SRS re-irradiation which was also given concurrently with chemotherapy. No pain flare or vertebral compression fractures were observed. MD Anderson has published outcomes for 48 patients with 66 spinal sarcoma metastases treated with SRS, of whom the median age was 53 years (range, 17-85) with $6 \%$ of lesions representing osteosarcoma or Ewing sarcoma metastases (35). While applicability to pediatric patients is somewhat limited by these demographics, the results are useful for efficacy and safety considerations when treating oligometastatic pediatric patients. The authors reported actuarial local control rate of $81 \%$ at 1 year for all patients. Multivariate analysis revealed significantly improved local control associated with biological equivalent dose (BED) $>48$ Gy and involvement of a single vertebral body, while there was a trend toward worse local control with postoperative SRS compared to definitive (subhazard ratio $2.33, \mathrm{P}=0.06$ ). Of all local recurrences, $78 \%$ occurred at the margin with the majority of recurrences located in the epidural space. Late toxicities included 4 insufficiency fractures and 3 cases of neuropathy. Of note, 2 of the 3 patients with osteosarcoma experienced local failure, while the single patient with Ewing sarcoma had durable local control at last follow-up.

Together, these data for SBRT and SRS demonstrate favorable local control rates with acceptably low rates of late toxicity. For further details on these data, Table 2 is a summary of recently published studies investigating SBRT for metastasis-directed therapy for pediatric patients.

\section{SBRT-clinical trials}

We hope to learn more from the analyses of prospective trials that incorporated SBRT into the treatment paradigm. Local consolidative radiotherapy to primary and metastatic disease has been incorporated into current protocols for Ewing sarcoma. The St. Jude Ewing sarcoma family of tumors (ESFT)13 (NCT01946529) is a trial of novel systemic agents and local therapy for ESFT and desmoplastic small round cell tumors. This trial utilizes metastasis-directed radiotherapy at week 19 of systemic therapy using either external beam radiotherapy (EBRT) with 54 Gy in 30 fractions ( $\mathrm{fx}$ ) or hypofractionated SBRT with $30 \mathrm{~Gy}$ in $6 \mathrm{fx}$ (44). Additionally, the Children's Oncology Group (COG) EWS1221 (NCT02306161) is a recently closed prospective phase III trial evaluating the addition of Ganitumab to multi-agent chemotherapy for newly-diagnosed metastatic Ewing sarcoma. This trial utilized local therapy with either surgery or radiotherapy to all initially involved sites of metastasis after completion of consolidation chemotherapy. Radiotherapy was either EBRT with $55.8 \mathrm{~Gy}$ in $31 \mathrm{fx}$ or SBRT with $40 \mathrm{~Gy}$ in $5 \mathrm{fx}$, although SBRT was reserved for lesions less than $5 \mathrm{~cm}$ in maximum diameter (45). There is also a recently closed multi-institutional single-arm phase II trial (NCT01763970) of SBRT with 40 Gy in 5 fractions for patients ages 3 to 40 years old with oligometastatic pediatric sarcoma with local control at 6 months as the primary endpoint (37). The authors define oligometastatic disease as 1 to 5 bony sites of unresectable metastatic disease, with greatest tumor dimension of all sites $\leq 5.0 \mathrm{~cm}$ or total volume of metastatic disease $<250 \mathrm{cc}$. This trial utilizes a SBRT regimen of 40 Gy in $5 \mathrm{fx}$ given over 1 to 2 weeks. The early results have now been presented in abstract form and included 14 patients who underwent SBRT to 32 bony metastases (37). The primary endpoint of lesion-specific local control at 6 months was $93 \%$, and median PFS and OS were 6.8 and 23.3 months, respectively. The median number of sites treated was 3 (range, 1-4 sites), and histologies included Ewing sarcoma $(50 \%)$, osteosarcoma (16\%) and high-grade soft tissue sarcoma (34\%). Two grade 3 toxicities were observed including radial fracture and dysphagia. 
Table 2 Metastasis-directed SBRT

\begin{tabular}{|c|c|c|c|c|c|c|c|}
\hline Study & Patients & $\begin{array}{l}\text { Treated } \\
\text { lesions }\end{array}$ & Tumor histology & $\begin{array}{l}\text { Median prescription } \\
\text { (range) }\end{array}$ & Local control & Toxicity & $\begin{array}{l}\text { Factors } \\
\text { associated with } \\
\text { local control }\end{array}$ \\
\hline $\begin{array}{l}\text { Brown } \\
\text { et al. (29) }\end{array}$ & 14 & 27 & OS (70\%); ES (30\%) & $\begin{array}{l}40 \text { Gy }[16-50] \text { in } \\
5 \text { fx [1-10] }\end{array}$ & $85 \%$ (2 years) & $\begin{array}{l}\text { Late Grade } 3: 7 \% \\
\text { Grade } \geq 4: \text { none }\end{array}$ & NR \\
\hline $\begin{array}{l}\text { Stragliotto } \\
\text { et al. (30) }\end{array}$ & 46 & 136 & $\begin{array}{l}\text { STS }(61 \%) ; \text { US (15\%); } \\
\text { OS (11\%); ES (11\%); } \\
\text { other }(13 \%)\end{array}$ & $\begin{array}{l}\text { Reported in EQD2: } \\
70 \text { Gy [26-162] in } \\
4 \text { fx [1-5] }\end{array}$ & $\begin{array}{l}88 \% \\
\text { (21 months) }\end{array}$ & $\begin{array}{l}1 \text { colonic } \\
\text { perforation, } 1 \text { hip } \\
\text { contracture }\end{array}$ & $\begin{array}{l}\text { Higher CR rate for } \\
\text { uterine sarcoma } \\
(71 \%)\end{array}$ \\
\hline $\begin{array}{l}\text { Parsai } \\
\text { et al. (32) }\end{array}$ & 22 & 61 & $\begin{array}{l}\text { OS }(45 \%) \text {; OS }(32 \%) \text {; } \\
\text { other }(23 \%)\end{array}$ & $\begin{array}{l}35 \text { Gy }[16-60] \text { in } \\
5 \text { fx }[1-5]\end{array}$ & $\begin{array}{l}87 \%(6 \\
\text { months); } 77 \% \\
\text { (12 months) }\end{array}$ & $\begin{array}{l}\text { Grade } 3 \text { enteritis: } \\
4.5 \%\end{array}$ & NR \\
\hline $\begin{array}{l}\text { Deck } \\
\text { et al. (33) }\end{array}$ & 3 & 12 & ES (33\%); other (67\%) & $\begin{array}{l}40 \text { Gy }[37.5-50] \text { in } \\
4 \text { fx [4-5] }\end{array}$ & $\begin{array}{l}100 \% \\
\text { (22 months) }\end{array}$ & None & NR \\
\hline $\begin{array}{l}\text { Chang } \\
\text { et al. (34) }\end{array}$ & 27 & 32 & OS (52\%); other (48\%) & $\begin{array}{l}21.8 \text { Gy [16-45] in } \\
1 \mathrm{fx}[1-3]\end{array}$ & $\begin{array}{l}96.7 \% \\
(6 \text { months); } \\
76.9 \% \text { (2 years) }\end{array}$ & NR & $\begin{array}{l}\text { Improved local } \\
\text { PFS if age } \leq 45 \\
(59 \text { vs. } 19 \text { mo, } \\
P=0.006)\end{array}$ \\
\hline $\begin{array}{l}\text { Parsai } \\
\text { et al. (36) }\end{array}$ & 7 & 11 & ES (55\%); OS (45\%) & $\begin{array}{l}35 \text { Gy [16-40] in } \\
5 \text { fx [1-5] }\end{array}$ & $\begin{array}{l}73 \% \\
\text { (11 months) }\end{array}$ & $\begin{array}{l}\text { Grade } 3 \text { enteritis: } \\
14 \%\end{array}$ & NR \\
\hline $\begin{array}{l}\text { Elledge } \\
\text { et al. (37) }\end{array}$ & 14 & 32 & $\begin{array}{l}\text { ES (50\%); OS (16\%); } \\
\text { STS (34\%) }\end{array}$ & 40 Gy in $5 \mathrm{fx}$ & $\begin{array}{l}93 \% \\
\text { (6 months) }\end{array}$ & $\begin{array}{l}\text { Grade 1: } 43 \% \text {; } \\
\text { Grade 3: } 14 \% \text { (one } \\
\text { left radius fracture, } \\
\text { one dysphagia) }\end{array}$ & NR \\
\hline $\begin{array}{l}\text { Chandy } \\
\text { et al. (38) }\end{array}$ & 14 & 18 & $\begin{array}{l}\text { ES }(21 \%) ; \text { MB }(21 \%) \text {; } \\
\text { ependymoma }(21 \%) ; \\
\text { NB }(14 \%)\end{array}$ & $\begin{array}{l}\text { Intracranial: } 19 \\
\text { Gy [18-24] in } 1 \mathrm{fx} \\
\text { extracranial: } 27 \mathrm{~Gy} \\
\text { [27-42] in } 3 \mathrm{fx} \text { [3-5] }\end{array}$ & $\begin{array}{l}\text { Intracranial: } \\
75 \% \text { (2 years); } \\
\text { extracranial: } \\
50 \% \text { (2 years) }\end{array}$ & $\begin{array}{l}\text { Intracranial, late } \\
\text { grade 3: } 38 \% \text {; } \\
\text { extracranial: no } \\
\text { late toxicity }\end{array}$ & NR \\
\hline
\end{tabular}

ES, Ewing sarcoma; CS, chondrosarcoma; OS, osteosarcoma; LMS, leiomyosarcoma; RMS, rhabdomyosarcoma; SC, spindle cell; STS, soft tissue sarcoma; FS, fibrosarcoma; MFH, malignant fibrous histiocytoma; HP, hemangiopericytoma; LS, liposarcoma; US, uterine sarcoma; NB, neuroblastoma; MB, medulloblastoma; NR, not reported; fx, fraction; VCF, vertebral compression fracture. 


\section{SBRT simulation and planning}

CT-simulation should be customized to the location of the targeted lesion. In general, thin-slice (1 or $1.5 \mathrm{~mm}$ ) CTsimulation images should be obtained in the treatment position with utilization of appropriate motion management systems. Simulation CT images are co-registered to a highdefinition treatment-planning MRI when the target lesion is located in the spine, extremity, or pelvis. If unable to obtain an MRI for a spine SRS patient, CT myelogram imaging may be obtained instead. Images are often obtained with intravenous and/or oral contrast depending on the location of the target. Immobilization can be achieved by means of vacuum immobilization devices for thoracic and abdominal targets or for spine SRS, a 5-point Aquaplast mask for spine SRS targets at the level of T5 and above, and smaller vacuum immobilization devices for extremity SBRT. Motion management techniques like inspiratory breath hold are often utilized for targets in the chest or upper abdomen as they allow for smaller target volumes when compared to abdominal compression with 4-dimensional CT (4DCT). However, very young patients require careful consideration in treatment planning as they are often unable to successfully perform inspiratory breath hold and may not tolerate abdominal compression. Additionally, very young patients may require general anesthesia for simulation and treatment. Targets and critical organs at risk are delineated by the radiation oncologist on axial images. Targets include a gross tumor volume (GTV) which is defined as visible gross disease based on all available imaging. With the exception of spine SRS, a clinical target volume (CTV) is created as a volumetric expansion of the GTV to account for microscopic disease within anatomically constrained region. For spine SRS, specific contouring guidelines exist for defining the CTV based on the location and size of the gross disease within the vertebral body (46). Finally, a planning target volume (PTV) is created which accounts for intra-fraction motion as well as inter-fraction motion due to potential setup error. Image-guidance is utilized with daily cone-beam computed tomography (CBCT) in the presence of a physician and physicist at the treatment console. For patients that have received prior radiotherapy, a composite of current and prior radiation plans is created to account for accumulated dose to organs at risk. Please refer to Figure 1 for a sample SBRT treatment plan for treatment of oligometastatic osteosarcoma.

\section{SBRT dose and fractionation}

SBRT is defined by the use of high doses of radiotherapy per fraction delivered to highly conformal targets in an extremely hypofractionated pattern, often 5 fractions or fewer (24). A commonly used dose for children and young adults is 40 Gy delivered in 5 fractions. However, for young children less than the age of 10 years old, a reduced dose of 35 Gy delivered in 5 fractions of 7 Gy per fraction can be considered as was utilized on the NCT01763970 trial of pediatric SBRT (47). There are multiple studies suggesting a spectrum of radiosensitivity among various primary histologies of metastatic tumors treated with SBRT $(48,49)$. In the pediatric population, this concept applies to osteosarcoma in particular which appears to exhibit relatively radioresistant behavior compared with other pediatric histologies treated with SBRT (50-54). The series from MD Anderson Cancer Center above demonstrated improved local control for spinal sarcoma metastases treated with SBRT when the BED was $>48$ Gy (35). In the Swedish trial of SBRT to metastatic sarcoma lesions, the authors describe utilization of inhomogeneous dose distribution within the PTV, with median PTV prescription isodose of $65 \%$ that allowed the central part of the PTV to receive doses roughly $50 \%$ higher than the prescription dose (30). The rationale for this technique is to deliver higher doses to a hypothetically more radioresistant population of hypoxic cells within the center of the PTV.

\section{Palliative radiotherapy for pediatric cancer patients}

The utility of radiotherapy in palliating cancer symptoms is well established in the pediatric population. Palliative RT strategies for pediatric patients range from conventionally fractionated external beam radiotherapy to hypofractionated dose-escalated RT similar to SBRT regimens mentioned above. Palliative radiotherapy for pediatric patients, often in combination with single- or multi-agent systemic therapy, is associated with pain relief as well as durable local control. A retrospective series from MD Anderson Cancer Center reported outcomes of conventional palliative RT delivered in conjunction with chemotherapy or 153-Samarium radioisotope therapy for pediatric patients with osteosarcoma (25). Thirty-nine patients with a median age of 14.7 years (range, 6-20) were treated with radiotherapy 


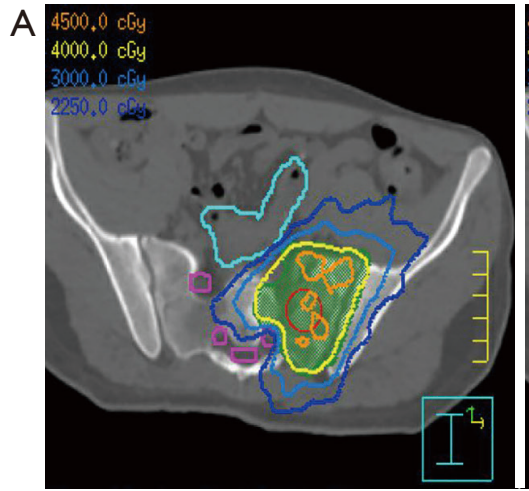

B

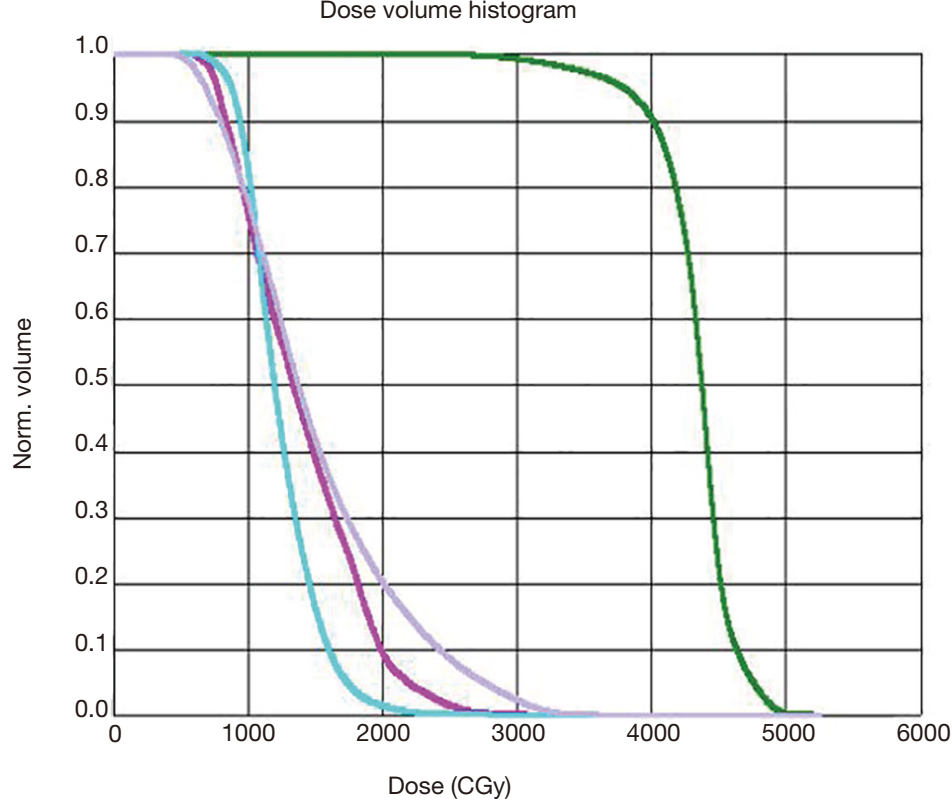

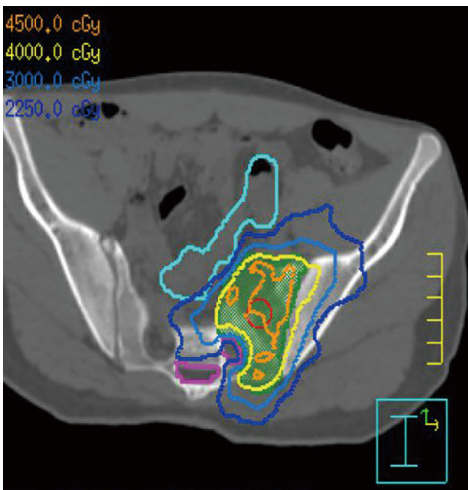

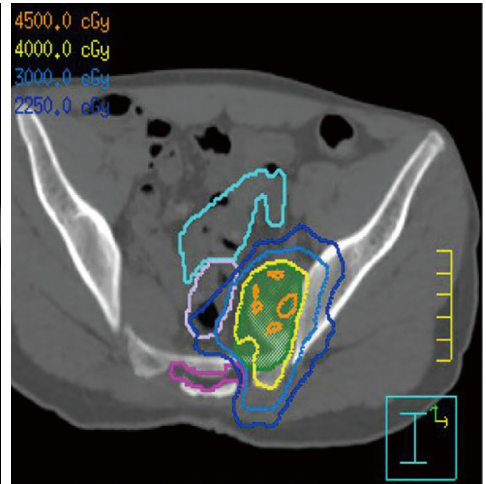

DVH Calculation

$\diamond$ Cumulative

$\checkmark$ Differential

Dose Axis Display

$\checkmark$ Normalized Dose

$\curvearrowright$ Absolute Dose

A Auto-Compute Max

$\checkmark$ Specify Max Dose

Volume Axis Display

A Normalized Volume

$\checkmark$ Absolute Volume

Tabular DVH

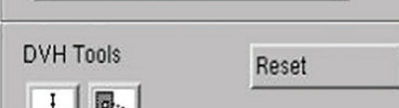

\begin{tabular}{|c|c|c|c|c|c|c|c|c|c|c|}
\hline \multicolumn{10}{|c|}{ ROI Statistics } & \multirow{2}{*}{$\begin{array}{l}\text { Compute } \\
\text { Generalized } \\
\text { EUD }\end{array}$} \\
\hline & $\begin{array}{l}\text { Line } \\
\text { Type }\end{array}$ & ROI & $\begin{array}{l}\text { Trial or } \\
\text { Record }\end{array}$ & Min. & Max. & Mean & Std. Dev. & $\begin{array}{l}\text { \% Outside } \\
\text { Grid }\end{array}$ & $\%>\operatorname{Max}$ & \\
\hline$\checkmark$ & - & sacral tumor & Reviewed and Appro & 1937.8 & 5192.7 & 4324.6 & 315.7 & $0.00 \%$ & $0.00 \%$ & -- \\
\hline$\diamond$ & - & sacral plexus & Reviewed and Appro & 531.1 & 3056.5 & 1389.2 & 455.4 & $0.00 \%$ & $0.00 \%$ & -- \\
\hline$\vartheta$ & - & small bowel & Reviewed and Appro & 619.9 & 2798.2 & 1240.6 & 271.9 & $0.00 \%$ & $0.00 \%$ & -- \\
\hline
\end{tabular}

Figure 1 A sample SBRT treatment plan for treatment of oligometastatic osteosarcoma. (A) Axial CT images of SBRT plan of 40 Gy/5 fx for oligometastatic osteosarcoma in the pelvis of a 17-year-old patient. Isodose lines are delineated in the legend, and organ at risk contours include sacral nerves (pink), rectum (periwinkle) and small bowel (teal). (B) Dose volume histogram for the SBRT plan pictured in (A). SBRT, stereotactic body radiotherapy. 
to 119 sites with a median dose of 30 Gy (range, 10-70) in 10 fractions (range, 4-35). Most patients (80\%) were receiving chemotherapy concurrently, most commonly ifosfamide or methotrexate. Of the painful sites, $76 \%$ experienced improvement, $10 \%$ had no change, and $13 \%$ had more pain after treatment. Local control, as determined by persistent and sustained reduction of standard uptake values on PET-CT and bone scan, was favorable with $72 \%$ of patients exhibiting radiographic improvement, $25 \%$ with stable findings, and 3\% with progression. Metastasis-free survival at 4 years was shown to be $39 \%$, and the median time to new metastasis at the time of RT was 15.2 months (range, 2-28).

In addition to pain, palliative RT can also help ameliorate dyspnea and neurologic symptoms. Retrospective data from Stanford reports favorable symptom relief, local control and toxicity outcomes after conventional dose-escalated palliative RT for metastatic and recurrent pediatric osteosarcoma (55). Twenty pediatric patients, median age of 17.9 years (range, 6.3-34.8), with symptomatic metastatic or locally recurrent disease were treated with 32 courses of palliative RT. Median RT dose in EQD2 was 40.0 Gy (range, 20-60.4) delivered in a median of 15 fractions (range, 5-39), reflecting moderate dose-escalation compared to typical palliative doses for less radioresistant histologies. Symptom relief was seen in $75 \%$ of patients at median time of 15.5 days (range, 3-43). Local failure was seen in $21.4 \%$ of patients at median follow-up time of 17.5 months (range, 2-102), with median time to progression of 12.9 months (range, 4-22). Higher EQD2 was correlated with more durable local control ( $\mathrm{r}=0.39, \mathrm{P}=0.0003)$.

Compared with conventionally fractionated RT, hypofractionated palliative RT has the advantage of convenience due to fewer visits to the treatment center. This can be especially relevant for significantly symptomatic patients. Hypofractionated palliative RT was shown to have favorable local control and response rates in pediatric patients with metastatic and recurrent cancers in a retrospective series from Memorial Sloan Kettering Cancer Center (24). Sixtytwo patients with median age of 12 years (range, 3-18) were treated with hypofractionated RT to 104 lesions. Median dose was 24 Gy (range, 15-40) in a median of 5 fractions (range, 3-5), of whom 2D/3D Conformal RT technique was used in $46 \%$, SBRT in $25 \%$, IMRT in $23 \%$, Electron RT in $4 \%$, and Proton RT in $2 \%$. Distribution of histology by lesion were $48 \%$ neuroblastoma, 16\% osteosarcoma, $13 \%$ Ewing sarcoma, and 23\% other histologies.

Together, these data propose treatment strategies for utilization of palliative RT in treating oligometastatic pediatric patients that may have poor performance status or other limitations to more aggressive therapy.

\section{Special considerations for the pediatric population}

\section{Toxicity with aggressive local therapy}

Toxicities from aggressive local radiotherapy can be significant for pediatric patients. Late toxicity is a particular concern when higher total doses and higher doses per fraction are employed in treating radioresistant histologies common to pediatric patients (56). Fortunately, with technological advancement resulting in ability to deliver highly conformal radiotherapy, toxicity profiles of SBRT and other hypofractionated RT regimens are favorable as shown above. Retrospective data from Memorial Sloan Kettering Cancer Center reported toxicity outcomes for 15 patients treated with SBRT to 20 lesions of multiple pediatric histologies including neuroblastoma, Ewing sarcoma, rhabdomyosarcoma, and osteosarcoma (27). Common toxicities included grade 1 dermatitis $(45 \%)$ and fatigue (40\%), and crude grade 3 toxicity rate was $15 \%$.

When it comes to characterizing and quantifying toxicity associated with aggressive therapy for pediatric cancer, it is unclear whether adolescent and young adult (AYA) patients experience toxicity more similarly to adults or young children. Investigators from Cincinnati Children's Hospital Medical Center are in the process of analyzing toxicity profiles in AYA patients across heterogeneous cancer diagnoses and treatment. The investigators are using machine learning for this analysis having previously seen promising results among acute lymphoblastic leukemia patients as discussed at a recent COG breakout session on toxicity.

Vertebral compression fracture is a well-recognized adverse event observed in some patients after spine SRS. While not specific to pediatric patients, retrospective data from the adult population can inform dose and fractionation selection for pediatric and AYA patients undergoing spine SRS. A multi-institutional study evaluating risk factors predicting VCF after spine SRS observed higher risk of VCF on multivariable analysis when dose per fraction exceeded 24 Gy (57).

\section{Toxicity after re-irradiation}

Management of locally recurrent oligometastatic disease in 
a previously irradiated area can be particularly challenging with regard to acute and late toxicity, especially when considering hypofractionated or stereotactic radiotherapy. Concurrent chemotherapy and re-irradiation were both associated with higher rates of toxicity in the retrospective series above. Normal tissue that has received radiation in the past does not completely repair damage by the time a repeat course of radiation is given (56). Re-irradiation with SBRT within 6 months of prior radiotherapy seems to confer a higher risk of toxicity as seen in retrospective data from Memorial Sloan Kettering Cancer Center (27). One patient with neuroblastoma experienced extremely painful, grade 3 myositis after re-irradiation to the scapula and distal femur with a 27 Gy SBRT regimen. Both sites were areas of synchronous oligometastasis that had received $30 \mathrm{~Gy}$ in 10 fractions within the previous 6 months. Another patient with osteosarcoma suffered grade 3 neuropathy after SBRT with 30 Gy in 3 fractions to the sacrum roughly 6 months after 79.2 CGE fractionated proton RT. Gultekin et al. report local control and toxicity outcomes for 23 pediatric patients undergoing reirradiation with hypofractionated SBRT, of whom $18 \%$ had extracranial disease, mostly in the spine (58). No acute or late toxicity was reported in the patients with extracranial disease. Similarly, in a series from the Royal Marsden Hospital evaluating toxicity in the setting of radiosurgery for oligometastatic patients (median age 15), higher rates of toxicity were seen for those with CNS treatment (38). This series found that a cumulative BED ( $\alpha / \beta$ of 2$)$ of greater than 200 Gy resulted in a higher probability of experiencing late toxicity $(\mathrm{P}=0.04)$. In the study by Stragliotto et al., 5 patients underwent reirradiation with SBRT. While the retrospective review was limited in ability to evaluate toxicity, the authors reported only two cases of serious side effects: one case of colonic perforation and one case of hip contracture, neither of which were fatal (30). Taunk et al. reported a crude grade 3 toxicity rate of $15 \%$ among the 15 patients with 20 lesions treated with SBRT, 12 of which were previously treated with radiotherapy (27). However, caution should be exercised in interpreting these findings as they were only presented in an abstract form and long-term follow-up data are not available.

When considering re-irradiation with spine SRS, clinicians can again extrapolate from data in adult patients to inform dose and fractionation selection. A Canadian retrospective series reported zero instances of VCF among 40 adult patients with 56 spine lesions treated with 30 Gy/4 fx salvage SRS (59). The median prior dose in this study was $24 \mathrm{~Gy} / 2 \mathrm{fx}$.

\section{Radiation recall reaction}

The phenomenon of radiation recall reaction is a rare late toxicity characterized by acute inflammation in a previously irradiated area upon administration of a systemic agent days to years later $(60,61)$. This is particularly relevant in counseling patients and families in the pediatric oligometastatic population for whom local radiotherapy will most likely be followed with additional systemic therapy. Radiation recall has been observed with administration of gemcitabine, sorafenib, cyclophosphamide, doxorubicin, vincristine, and other systemic agents (62-68).

\section{Conclusions}

While the pediatric oligometastasis treatment paradigm lacks standardized clinical guidelines at the time of this review, the retrospective data above have led to promising prospective trials that will further elucidate optimum management of these patients. Overall, metastasis-directed therapy has generally been shown to be well-tolerated, associated with favorable local control, and shown in select patients to improve event-free survival and PFS outcomes. Further studies are needed to more clearly define patient selection criteria.

\section{Acknowledgments}

Funding: None.

\section{Footnote}

Provenance and Peer Review: This article was commissioned by the Guest Editors (Simon Lo, Michael Milano, Tithi Biswas, Charles Simone) for the series "OligometastasisFallacy or Real Deal?" published in Annals of Palliative Medicine. The article has undergone external peer review.

Reporting Checklist: The authors have completed the NARRATIVE REVIEW reporting checklist. Available at http://dx.doi.org/10.21037/apm-20-1023

Conflicts of Interest: All authors have completed the ICMJE uniform disclosure form (available at http://dx.doi. 
org/10.21037/apm-20-1023). The series “OligometastasisFallacy or Real Deal?" was commissioned by the editorial office without any funding or sponsorship. The authors have no other conflicts of interest to declare.

Ethical Statement: The authors are accountable for all aspects of the work in ensuring that questions related to the accuracy or integrity of any part of the work are appropriately investigated and resolved.

Open Access Statement: This is an Open Access article distributed in accordance with the Creative Commons Attribution-NonCommercial-NoDerivs 4.0 International License (CC BY-NC-ND 4.0), which permits the noncommercial replication and distribution of the article with the strict proviso that no changes or edits are made and the original work is properly cited (including links to both the formal publication through the relevant DOI and the license). See: https://creativecommons.org/licenses/by-nc-nd/4.0/.

\section{References}

1. Siegel RL, Miller KD, Jemal A. Cancer statistics, 2018. CA Cancer J Clin 2018;68:7-30.

2. Kushner BH, Cheung NK, Barker CA, et al. Hyperfractionated low-dose (21 Gy) radiotherapy for cranial skeletal metastases in patients with highrisk neuroblastoma. Int J Radiat Oncol Biol Phys 2009;75:1181-6

3. Dix DB, Seibel NL, Chi YY, et al. Treatment of Stage IV Favorable Histology Wilms Tumor With Lung Metastases: A Report From the Children's Oncology Group AREN0533 Study. J Clin Oncol 2018;36:1564-70.

4. Ehrlich PF, Ferrer FA, Ritchey ML, et al. Hepatic metastasis at diagnosis in patients with Wilms tumor is not an independent adverse prognostic factor for stage IV Wilms tumor: a report from the Children's Oncology Group/National Wilms Tumor Study Group. Ann Surg 2009;250:642-8.

5. Combination Chemotherapy, Radiation Therapy, and/ or Surgery in Treating Patients With High-Risk Kidney Tumors. Available online: https://clinicaltrials.gov/ct2/ show/NCT00335556

6. Casey DL, Wexler LH, Meyers PA, et al. Radiation for bone metastases in Ewing sarcoma and rhabdomyosarcoma. Pediatr Blood Cancer 2015;62:445-9.

7. Weigel BJ, Lyden E, Anderson JR, et al. Intensive Multiagent Therapy, Including Dose-Compressed
Cycles of Ifosfamide/Etoposide and Vincristine/ Doxorubicin/Cyclophosphamide, Irinotecan, and Radiation, in Patients With High-Risk Rhabdomyosarcoma: A Report From the Children's Oncology Group. J Clin Oncol 2016;34:117-22.

8. Chemotherapy and Radiation Therapy in Treating Young Patients With Newly Diagnosed, Previously Untreated, High-Risk Medulloblastoma/PNET. Available online: https://clinicaltrials.gov/ct2/show/NCT00392327

9. Ladenstein R, Potschger U, Le Deley MC, et al. Primary disseminated multifocal Ewing sarcoma: results of the Euro-EWING 99 trial. J Clin Oncol 2010;28:3284-91.

10. Hellman S, Weichselbaum RR. Oligometastases. J Clin Oncol 1995;13:8-10.

11. Palma DA, Haasbeek CJ, Rodrigues GB, et al. Stereotactic ablative radiotherapy for comprehensive treatment of oligometastatic tumors (SABR-COMET): study protocol for a randomized phase II trial. BMC Cancer 2012;12:305.

12. Gomez DR, Blumenschein GR Jr, Lee JJ, et al. Local consolidative therapy versus maintenance therapy or observation for patients with oligometastatic non-smallcell lung cancer without progression after first-line systemic therapy: a multicentre, randomised, controlled, phase 2 study. Lancet Oncol 2016;17:1672-82.

13. Iyengar P, Wardak Z, Gerber DE, et al. Consolidative Radiotherapy for Limited Metastatic Non-Small-Cell Lung Cancer: A Phase 2 Randomized Clinical Trial. JAMA Oncol 2018;4:e173501.

14. Ruers T, Van Coevorden F, Punt CJA, et al. Local Treatment of Unresectable Colorectal Liver Metastases: Results of a Randomized Phase II Trial. J Natl Cancer Inst 2017;109:djx015.

15. Trovo M, Furlan C, Polesel J, et al. Radical radiation therapy for oligometastatic breast cancer: Results of a prospective phase II trial. Radiother Oncol 2018;126:177-80.

16. Haeusler J, Ranft A, Boelling T, et al. The value of local treatment in patients with primary, disseminated, multifocal Ewing sarcoma (PDMES). Cancer 2010;116:443-50.

17. Weinlechner J. Tumoren an der Brustwand und deren Behnadlung (resection der Rippen) Eroffnung der Brusthohle und partielle Entfernung der Lunge. Wien Med Wschr 1882;32:590.

18. Pastorino U, Gasparini M, Tavecchio L, et al. The contribution of salvage surgery to the management of childhood osteosarcoma. J Clin Oncol 1991;9:1357-62.

19. Pastorino U. Lung metastasectomy for colorectal cancer. 
Tumori 1997;83:S28-30.

20. Breneman JC, Lyden E, Pappo AS, et al. Prognostic factors and clinical outcomes in children and adolescents with metastatic rhabdomyosarcoma--a report from the Intergroup Rhabdomyosarcoma Study IV. J Clin Oncol 2003;21:78-84.

21. Grewal AS, Li Y, Grewal SK, et al. Role of Metastatic Site Irradiation in Pediatric Patients With Metastatic Ewing Sarcoma. J Pediatr Hematol Oncol 2020;42:e305-9.

22. Mohan AC, Venkatramani R, Okcu MF, et al. Local therapy to distant metastatic sites in stage IV rhabdomyosarcoma. Pediatr Blood Cancer 2018;65:e26859.

23. Kandula S, Prabhu RS, Nanda R, et al. Outcomes After Radiation Therapy to Metastatic Sites in Patients With Stage 4 Neuroblastoma. J Pediatr Hematol Oncol 2015;37:175-80.

24. Lazarev S, Kushner BH, Wolden SL. Short Hypofractionated Radiation Therapy in Palliation of Pediatric Malignancies: Outcomes and Toxicities. Int J Radiat Oncol Biol Phys 2018;102:1457-64.

25. Mahajan A, Woo SY, Kornguth DG, et al. Multimodality treatment of osteosarcoma: radiation in a high-risk cohort. Pediatr Blood Cancer 2008;50:976-82.

26. Benedict SH, Yenice KM, Followill D, et al. Stereotactic body radiation therapy: The report of AAPM Task Group 101. Med Phys 2010;37:4078-101.

27. Taunk NK, Wolden SL. Acute Toxicity and Local Control in Pediatric Cancers Treated With Stereotactic Body Radiation Therapy (SBRT). Int J Radiat Oncol Biol Phys 2015;93:E508-9.

28. Tinkle CL, Singh C, Hyun JW, et al. Stereotactic Body Radiotherapy for Metastatic and Recurrent Lesions in Pediatric Patients. Int J Radiat Oncol Biol Phys 2017;99:E572.

29. Brown LC, Lester RA, Grams MP, et al. Stereotactic body radiotherapy for metastatic and recurrent Ewing sarcoma and osteosarcoma. Sarcoma 2014;2014:418270.

30. Stragliotto CL, Karlsson K, Lax I, et al. A retrospective study of SBRT of metastases in patients with primary sarcoma. Med Oncol 2012;29:3431-9.

31. Kim E, Jeans E, Shinohara ET, et al. Stereotactic Body Radiotherapy (SBRT) for Metastatic and Recurrent Soft Tissue and Bone Sarcomas. Int J Radiat Oncol Biol Phys 2017;99:E754.

32. Parsai S, Sedor G, Scott JG, et al. Multi-Site SBRT for Pediatric, Adolescent, and Young Adult Patients with Metastatic Sarcoma: Early Outcomes and Safety Data. Int J Radiat Oncol Biol Phys 2019;105:S186-7.
33. Deck J, Eastwick G, Sima J, et al. Efficacy and tolerability of stereotactic body radiotherapy for lung metastases in three patients with pediatric malignancies. Onco Targets Ther 2019;12:3723-7.

34. Chang UK, Cho WI, Lee DH, et al. Stereotactic radiosurgery for primary and metastatic sarcomas involving the spine. J Neurooncol 2012;107:551-7.

35. Bishop AJ, Tao R, Guadagnolo BA, et al. Spine stereotactic radiosurgery for metastatic sarcoma: patterns of failure and radiation treatment volume considerations. J Neurosurg Spine 2017;27:303-11.

36. Parsai S, Juloori A, Angelov L, et al. Spine radiosurgery in adolescents and young adults: early outcomes and toxicity in patients with metastatic Ewing sarcoma and osteosarcoma. J Neurosurg Spine 2019. [Epub ahead of print].

37. Elledge CR, Krasin M, Han P, et al. A Multi-Institutional Prospective Phase II Trial of Hypofractionated Stereotactic Body Radiotherapy (SBRT) in the Treatment of Metastatic Pediatric Sarcomas of Bone Sites. Int J Radiat Oncol Biol Phys 2019;105:S186.

38. Chandy E, Taylor H, Gaito S, et al. Hypofractionated Stereotactic Ablative Radiotherapy for Recurrent or Oligometastatic Tumours in Children and Young Adults. Clin Oncol (R Coll Radiol) 2020;32:316-26.

39. Levine AM, Coleman C, Horasek S. Stereotactic radiosurgery for the treatment of primary sarcomas and sarcoma metastases of the spine. Neurosurgery 2009;64:A54-9.

40. Spratt DE, Arevalo-Perez J, Leeman JE, et al. Early magnetic resonance imaging biomarkers to predict local control after high dose stereotactic body radiotherapy for patients with sarcoma spine metastases. Spine J 2016;16:291-8.

41. Miller JA, Balagamwala EH, Angelov L, et al. Stereotactic Radiosurgery for the Treatment of Primary and Metastatic Spinal Sarcomas. Technol Cancer Res Treat 2017;16:276-84.

42. Elibe E, Boyce-Fappiano D, Ryu S, et al. Stereotactic radiosurgery for primary tumors of the spine and spinal cord(dagger). J Radiosurg SBRT 2018;5:107-13.

43. Karimi AM, Campbell SR, Parsai S, et al. Aggressive Local Control With Multisite Stereotactic Body Radiation in Metastatic Ewing Sarcoma: A Literature Review and Case Report. Anticancer Res 2020;40:951-5.

44. Therapeutic Trial for Patients With Ewing Sarcoma Family of Tumor and Desmoplastic Small Round Cell Tumors. Available online: https://clinicaltrials.gov/ct2/ 
show/NCT01946529

45. Combination Chemotherapy With or Without Ganitumab in Treating Patients With Newly Diagnosed Metastatic Ewing Sarcoma. Available online: https://clinicaltrials.gov/ ct2/show/NCT02306161

46. Ryu S, Pugh SL, Gerszten PC, et al. RTOG 0631 phase $2 / 3$ study of image guided stereotactic radiosurgery for localized (1-3) spine metastases: phase 2 results. Pract Radiat Oncol 2014;4:76-81.

47. Stereotactic Radiation Therapy for Pediatric Sarcomas. Available online: https://clinicaltrials.gov/ct2/show/ NCT01763970

48. Woody NM, Stephans KL, Andrews M, et al. A Histologic Basis for the Efficacy of SBRT to the lung. J Thorac Oncol 2017;12:510-9.

49. Ahmed KA, Caudell JJ, El-Haddad G, et al. Radiosensitivity Differences Between Liver Metastases Based on Primary Histology Suggest Implications for Clinical Outcomes After Stereotactic Body Radiation Therapy. Int J Radiat Oncol Biol Phys 2016;95:1399-404.

50. Anderson PM. Effectiveness of radiotherapy for osteosarcoma that responds to chemotherapy. Mayo Clin Proc 2003;78:145-6.

51. Machak GN, Tkachev SI, Solovyev YN, et al. Neoadjuvant chemotherapy and local radiotherapy for high-grade osteosarcoma of the extremities. Mayo Clin Proc 2003;78:147-55.

52. DeLaney TF, Park L, Goldberg SI, et al. Radiotherapy for local control of osteosarcoma. Int J Radiat Oncol Biol Phys 2005;61:492-8.

53. Zuch D, Giang AH, Shapovalov Y, et al. Targeting radioresistant osteosarcoma cells with parthenolide. J Cell Biochem 2012;113:1282-91.

54. Feng H, Wang J, Chen W, et al. Hypoxia-induced autophagy as an additional mechanism in human osteosarcoma radioresistance. J Bone Oncol 2016;5:67-73.

55. Chen EL, Yoo CH, Gutkin PM, et al. Outcomes for pediatric patients with osteosarcoma treated with palliative radiotherapy. Pediatr Blood Cancer 2020;67:e27967.

56. Hall EJ, Giaccia AJ. Radiobiology for the radiologist. 8th ed. Philadelphia: Wolters Kluwer, 2019.

Cite this article as: Smile TD, Parsai S, Pflederer TM, Murphy ES. Treatment paradigms for oligometastatic pediatric cancers: a narrative review with a focus on radiotherapy approaches. Ann Palliat Med 2021;10(5):6002-6015. doi: 10.21037/ apm-20-1023
57. Sahgal A, Atenafu EG, Chao S, et al. Vertebral compression fracture after spine stereotactic body radiotherapy: a multi-institutional analysis with a focus on radiation dose and the spinal instability neoplastic score. J Clin Oncol 2013;31:3426-31.

58. Gultekin M, Cengiz M, Sezen D, et al. Reirradiation of Pediatric Tumors Using Hypofractionated Stereotactic Radiotherapy. Technol Cancer Res Treat 2017;16:195-202.

59. Thibault I, Campbell M, Tseng CL, et al. Salvage Stereotactic Body Radiotherapy (SBRT) Following InField Failure of Initial SBRT for Spinal Metastases. Int J Radiat Oncol Biol Phys 2015;93:353-60.

60. Burris HA 3rd, Hurtig J. Radiation recall with anticancer agents. Oncologist 2010;15:1227-37.

61. Camidge R, Price A. Characterizing the phenomenon of radiation recall dermatitis. Radiother Oncol 2001;59:237-45.

62. Hird AE, Wilson J, Symons S, et al. Radiation recall dermatitis: case report and review of the literature. Curr Oncol 2008; 15:53-62.

63. Hattangadi J, Esty B, Winey B, et al. Radiation recall myositis in pediatric Ewing sarcoma. Pediatr Blood Cancer 2012;59:570-2.

64. Eckardt MA, Bean A, Selch MT, et al. A child with gemcitabine-induced severe radiation recall myositis resulting in a compartment syndrome. J Pediatr Hematol Oncol 2013;35:156-61.

65. Jereczek-Fossa BA, Piperno G, Ronchi S, et al. Linacbased stereotactic body radiotherapy for oligometastatic patients with single abdominal lymph node recurrent cancer. Am J Clin Oncol 2014;37:227-33.

66. Hsieh CH, Lin SC, Shueng PW, et al. Recall radiation dermatitis by sorafenib following stereotactic body radiation therapy. Onco Targets Ther 2014;7:1111-4.

67. Kim GE, Song HS, Ahn KJ, et al. Radiation recall dermatitis triggered by sorafenib after radiation therapy for hepatocellular carcinoma. Radiat Oncol J 2017;35:289-94.

68. Ravishankar A, Park SS, Olivier KR, et al. GemcitabineInduced Radiation Recall Myositis: Case Report and Review of the Literature. Case Rep Oncol 2018;11:168-78. 